\title{
Comparison of the Protective Effects of Prostaglandin Analogues in the Ischemia and Reperfusion Model of Rabbit Eyes
}

\author{
Sinan EMRE ${ }^{1,5)}$, Mehmet GUL ${ }^{2)}$, Burhan ATES ${ }^{3)}$, Mukaddes ESREFOGLU ${ }^{2)}$, \\ Bekir $\mathrm{KOC}^{1)}$, Ali ERDOGAN ${ }^{3)}$, and Elif YESILADA ${ }^{4)}$
}

\begin{abstract}
${ }^{1)}$ Department of Ophthalmology, Faculty of Medicine, Inonu University, Malatya, ${ }^{2)}$ Department of Histology and Embryology, Faculty of Medicine, Inonu University, Malatya, ${ }^{3)}$ Department of Chemistry, Faculty of Science and Art, Inonu University, Malatya, ${ }^{4)}$ Department of Medical Biology and Genetics, Faculty of Medicine, Inonu University, Malatya, and ${ }^{5)}$ Pressent address: Department of Ophthalmology, Faculty of Medicine, Celal Bayar University, Manisa, Turkey
\end{abstract}

\begin{abstract}
This study was planned to investigate the neuroprotective potentials of three commercially available prostaglandin analogues (PGA), in the ischemia and reperfusion model (I/R). Thirty New Zealand rabbits were divided into 5 groups and except for the control group (non-ischemic, non-treated), $0.9 \% \mathrm{NaCl}$, bimatoprost, latanoprost, or travoprost were applied to both eyes of animals of the respective groups for 1 week. At the end of treatment, ischemia was induced in both eyes of the 4 treatment groups by anterior chamber irrigation of the animals for $60 \mathrm{~min}$. Following $24 \mathrm{~h}$ reperfusion, the animals were sacrified. Enucleated eyes and retinal tissues were investigated by light microscopy, electron microscopy, immunohistochemicstry for retinal histopathology, intracellular and apoptotic cells and by retinal morphometry. Vitreous samples were biochemically investigated for probable role of reactive oxygen species, by measuring xanthine oxidase $(X O)$ activity. Analysis of morphometric measurements and vitreous $X O$ activity revealed significant differences between the PGAtreated groups and the $\mathrm{NaCl}$-treated group $(P<0.05)$. Similarly, apoptotic cell counts in different retinal layers showed that PGA-treated groups had fewer apoptotic cells in all retinal layers than the $\mathrm{NaCl}$-treated ischemic group $(P<0.05)$. PGA may have high protective potential for different retinal layers and cells. Biochemical analysis of vitreous showed that all PGAs decreased vitreous $\mathrm{XO}$ activity significantly compared to the $\mathrm{NaCl}$-treated group $(P<0.05)$. However we could not find any statistically significant differences among the analogues. PGAs may reduce the injury induced by $\mathrm{I} / \mathrm{R}$, through the inhibition of $\mathrm{XO}$ activity, and it seems that their effects are elicited through numerous pathways.
\end{abstract}

Key words: bimatoprost, ischemia and reperfusion, latanoprost, travoprost, xanthine oxidase

\section{Introduction}

Retinal ischemia contributes to visual impairment and blindness in diseases such as acute closed angle glau- coma [36] and diabetic retinopathy [6]. Hypoxia leads disruption of the cellular energy metabolism and initiates several harmful cascades [1]. The generation of reactive oxygen species (ROS), degradation of the antioxidant

(Received 27 March 2009 / Accepted 26 June 2009)

Address corresponding: S. Emre, Department of Ophthalmology, Faculty of Medicine, Celal Bayar University, Manisa, TR-45010 Malatya, Turkey 
system, induction of cytokine production via transcriptional factors, and extracellular accumulation of glutamate that is excitotoxic to neuronal elements are the main alterations secondary to ischemia $[1,16,18,19,34,38$, $40,41]$. Reperfusion after initial ischemia paradoxically maintains the destruction process, perhaps due to increased levels of extracellular neurotransmitters, ROS, and waste products damaging previously unharmed cells when being reoxidized $[1,5,28]$. In this process, it is considered that xanthine oxidase (XO) is a major source of ROS [22, 39].

Glaucoma is one of the major causes of irreversible blindness on all over the world. Vision loss in glaucoma is attributed to retinal ganglion cell loss, and raised intraocular pressure (IOP) is the major modifiable risk factor [15]. Although the clinical picture of glaucoma is well described, the exact mechanism leading to this specific type of damage is not yet clear [11]. One of the most frequently used models for the investigation of molecular mechanisms and potential therapeutic strategies for retinal ischemia has been an experimental model of acute elevation of IOP followed by reperfusion [43].

IOP-lowering treatment, either by use of topically applied drugs or by surgery, is the only treatment modality for glaucoma. Among various topical agents, prostaglandin analogues (PGA) are the newest class of glaucoma medications that have been introduced into the anti-glaucoma market. These medications have powerful ocular hypotensive effects through facilitated uveoscleral outflow. There are currently three internationally approved analogues (bimatoprost, latanoprost, and travoprost) for the treatment of patients with elevated intraocular pressure. In addition to the IOP lowering effect, a recent paper documented the retinal cell protective potential against ischemic conditions, in vivo and in vitro for latanoprost [10]. Clinically apoptosis has been shown to occur in retinas with glaucoma [27].

The aim of this study was to compare the anti-apoptototic potential of three prostoglandin analogues (bimatoprost, latanoprost, and travoprost) in the ischemia and reperfusion (I/R) model. We also aimed to investigate the potential of these agents against ROS production through the measurement of xanthine oxidase (XO) activity in vitreous.

\section{Materials and Methods}

Thirty adult male New Zealand rabbits, weighing 900 to $1,100 \mathrm{~g}$, were used in compliance with the ARVO Statement for the use of Animals in Ophthalmic and Vision Research. The animals were allowed free access to standard food diet and water in the animal laboratory at Inonu University. The animal handling and experimental protocol were reviewed and approved by the ethical committee for animal care and use of Inonu University. The rabbits were quarantined for 8 days at $22-24^{\circ} \mathrm{C}$ with a 12 -h light / 12 -h dark cycle before begining the experimental process for adaptation.

\section{Experimental model of ischemia and reperfusion}

The animals were randomly divided into 5 groups. No medication was applied to the animals of the first group ( $n=6)$ and this group is hereafter described as the control group. In the other 4 groups $(n=6)$, animals were treated with $0.9 \% \mathrm{NaCl}$, bimatoprost (Lumigan, Abdi Ibrahim Ilac Inc., Turkey), latanoprost (Xalatan, Pfizer Turkey Inc.), or travoprost (Travatan, Alcon Turkey Inc.) $1 \times 1 \mathrm{drop} /$ day for one week. At the end of one week, ischemia was created as described previously [9, 30,33]. In short, animals were anesthesized with ketamine (50 $\mathrm{mg} / \mathrm{kg}$ ) and xylazine $(5 \mathrm{mg} / \mathrm{kg}$ ) and topical anesthetic was dropped on to the cornea of the animals. A steel 30-gauge infusion needle connected to a saline reservoir, elevated to $1.70 \mathrm{~m}$, was inserted into the anterior chamber of both eyes of the animals. Except for the control group, the reservoir was opened for $60 \mathrm{~min}$ and the increase of intraocular pressure was monitored by indirect ophthalmoscopy by observing the cessation of blood flow at the optic disk. At the end of $60 \mathrm{~min}$, the cannulating needle was removed and intraocular pressure normalised by allowing reperfusion for $24 \mathrm{~h}$. At the end of the reperfusion period, the animals were sacrificed with an overdose of xylazin $(10 \mathrm{mg} / \mathrm{kg})$ and ketamin $(150 \mathrm{mg} / \mathrm{kg})$ and their eyeballs were removed for analysis.

\section{Preparation of tissue samples}

Both eyes of the animals were enucleated, and the left eyes were dissected quickly under a stereo microscope. The eyeball was cut posteriorly to the limbus, and there- 
after the anterior segment was discarded. Immediately, the vitreous was obtained for biochemical analysis, and the retina was carefully dissected from the sclera/choroid/pigment epithelium.

Xanthine oxidase $(\mathrm{XO})$ activity assay and protein level determination

$\mathrm{XO}$ activity was determined spectrophotometrically as described by Bergmeyer et al. [4]. To $50 \mathrm{mM}$ phosphate buffer, $\mathrm{pH} 7.5$, containing $1 \mathrm{mM}$ xanthine, aliquots of homogenate were added and changes in optical density were recorded at $290 \mathrm{~nm}$. One unit of XO was defined as $1 \mu \mathrm{mol}$ of xanthine converted to uric acid in 1 $\min$ at $\mathrm{pH} 7.5$ and $25^{\circ} \mathrm{C}$. The specific activity of $\mathrm{XO}$ was expressed in milli-units $(\mathrm{mU})$ per $\mathrm{mg}$ protein. Protein levels of the samples were measured spectrophotometrically according to the method of Lowry et al. [21].

Light microscopy and immunohistochemical evaluation

For light microscopic and immunohistochemical evaluation, right ocular globes were fixed in $10 \%$ neutral buffered formaldehyde and embedded in paraffin wax. Sections from paraffin blocks were cut at $5 \mu \mathrm{m}$, mounted on slides. Sections were stained with haematoxylin and eosin (HE) and then stained immunohistochemically using a TUNEL System (DeadEnd Colorimetric TUNEL System, Promega Corporation, Madison, USA) kit. The sections were observed, analysed and photographed using a Leica DFC280 light microscope and a Leica Q Win Image Analysis System (Leica Micros Imaging Solutions Ltd., Cambridge, UK).

\section{Electron microscopic examination}

For electron microscopic examination, samples of retina were fixed in $2.5 \%$ gluteraldehyde buffered with $0.2 \mathrm{M} \mathrm{NaH}_{2} \mathrm{PO}_{4}+\mathrm{NaHPO}_{4}(\mathrm{pH}=7.4)$ and postfixed in $1 \% \mathrm{OsO}_{4}$. After dehydration in acetone, they were embedded in Araldite CY 212. Ultrathin sections were stained with uranyl acetate and lead citrate and examined by a Zeiss Libra 120 transmission electron microscope.

\section{Immunohistochemical examination}

Five- $\mu \mathrm{m}$ thick sections were mounted on poly-Llysine coated slides, subsequently deparaffinized by immersion in xylene for $5 \mathrm{~min}$ at room temperature, then rehydrated in a graded alcohol series. A Colorimetric Apoptosis Detection System was used according to the manufacturer's instructions. Briefly, sections were treated with $20 \mu \mathrm{g} / \mathrm{ml}$ proteinase $\mathrm{K}$ for $10 \mathrm{~min}$, washed in PBS and refixed in $10 \%$ buffered formaldehyde in PBS and treated with equilibration buffer for $10 \mathrm{~min}$ at room temperature. Subsequently, add the rTdT (Terminal deoxynucleotidyl transferase) reaction mixwas added to the sections on the slides. The slides were incubated at $37^{\circ} \mathrm{C}$ for $60 \mathrm{~min}$ inside a humidified chamber. After washing, $0.3 \%$ hydrogen peroxidase was used to block endogenous peroxidase. Streptavidin HRP (1:500 in PBS) was added for $30 \mathrm{~min}$ at room temperature. DNA strand breaks were visualized by using hydrogen peroxidase and chromogen 3,3'-diaminobenzidine tetrahydrochloride. Sections were counterstained with haematoxylin. Negative controls were performed by omitting TdT enzyme.

\section{Morphometric analysis}

The thickness of retinal layers was measured on 10 different sections under the light microscope with $\times 40$ objective lens. The TUNEL-positive cells at the ganglion cell layer (GCL), the inner nuclear layer (INL) and the outer nuclear layer (ONL) were counted on 10 different sections under the light microscope with $\times 40$ objective lens.

\section{Statistical analysis}

Statistical analysis was performed with SPSS for Windows version 12.0 program (SPPS Inc., Chicago, IL). All data are reported as means \pm standard error of mean (SEM). For statistical analysis of retinal thickness measurements among groups the Mann-Whitney $\mathrm{U}$ was test used. For statistical analysis of XO measurements, variables in groups were determined by the Shapire Wilk test. The variables did not show normal distribution $(P>0.05)$. So, the Kruskal Wallis test and the MannWhitney U test with Bonferroni correction were used for comparisons of variables among and between the studied groups. A value of $P<0.05$ was considered statistically significant. 
Table 1. Mean \pm SEM thickness of retinal layers in microns $(\mu)$ among study groups

\begin{tabular}{|c|c|c|c|c|c|}
\hline Group & GCL & INL & ONL & PRL & Total \\
\hline Control & $20.8 \pm 0.6$ & $20.2 \pm 0.8$ & $33.5 \pm 1.3$ & $30.3 \pm 0.94$ & $125.3 \pm 1.6$ \\
\hline $\mathrm{I} / \mathrm{R}+\mathrm{NaCl}$ & $18.8 \pm 0.2^{\mathrm{a})}$ & $24.0 \pm 0.7^{\mathrm{a})}$ & $27.4 \pm 0.5^{\mathrm{a})}$ & $24.8 \pm 1.14^{\mathrm{a})}$ & $117.7 \pm 1.6^{\mathrm{a})}$ \\
\hline $\mathrm{I} / \mathrm{R}+$ Bimatoprost & $19.6 \pm 0.4$ & $22.4 \pm 0.3$ & $33.0 \pm 0.4^{\mathrm{b})}$ & $32.7 \pm 0.8^{\mathrm{b})}$ & $128.8 \pm 1.6^{\mathrm{b})}$ \\
\hline $\mathrm{I} / \mathrm{R}+$ Latanoprost & $20.3 \pm 1.0$ & $22.2 \pm 0.9$ & $34.6 \pm 1.1^{\mathrm{b})}$ & $33.0 \pm 1.1^{\mathrm{b})}$ & $129.7 \pm 3.6^{\mathrm{b})}$ \\
\hline $\mathrm{I} / \mathrm{R}+$ Travoprost & $20.0 \pm 1.2$ & $22.2 \pm 0.8$ & $33.6 \pm 1.5^{\mathrm{b})}$ & $33.3 \pm 0.8^{\mathrm{b})}$ & $128.3 \pm 1.6^{\mathrm{b})}$ \\
\hline
\end{tabular}

GCL: Ganglion cell layer, INL: Inner nuclear layer, ONL: Outer nuclear layer, PRL: Photoreceptor layer, I/R: Ischemia and reperfusion. ${ }^{\text {a) }}$ : Statistically significant difference compared to control group $P<0.05$. ${ }^{\text {b): }}$ Statistically significant difference compared to $\mathrm{I} / \mathrm{R}+\mathrm{NaCl}$ group $P<0.05$.

\section{Results}

\section{Light microscopy}

As shown in Table 1, morphometric analysis showed that treatment with PGA prevented atrophy of the retinal layers particularly ONL and photoreceptor layer (PRL) compared to the $\mathrm{NaCl}$-treated group. Under a light microscope, sections from the control group were normal in histological appearence (Fig. 1). However, in the $\mathrm{NaCl}$-treated group, a decrease in the number of cells in INL and ONL, loss in GCL, edema in INL (Table 1), nuclear condensation in ONL, and degeneration at the PRL were detected (Fig. 2). In the bimatoprost-treated group, the histological picture of the retina was very similar to that of the control group, except for mild edema in PRL (Fig. 3). In the latanoprost treatment group, minimal edema in ONL was noticed (Fig. 4). Finally, in the travoprost treatment group, there was minimal edema in INL and PRL (Fig. 5).

\section{Immunohistochemical analysis}

No apoptotic cell in any of the retinal layers was observed in the control group. However, following $I / R$, TUNEL-positive cells appeared as dark brown cells, as shown in Figs. 2, 3, 4, and 5. In the control group, we did not detect any TUNEL-positive cells in any layer. On the other hand, in the I/R group treated with $\mathrm{NaCl}$, TUNEL-positive cells increased throughout INL and GCL, and were much more intense and numerous in ONL (Fig. 2). In the bimatoprost and travoprost treatment groups, there were a few TUNEL-positive cells scattered throughout all the retinal layers (Figs. 3 and 5). In the latanoprost treatment group, TUNEL-positive cells were scattered in all retinal layers, but were more prominent
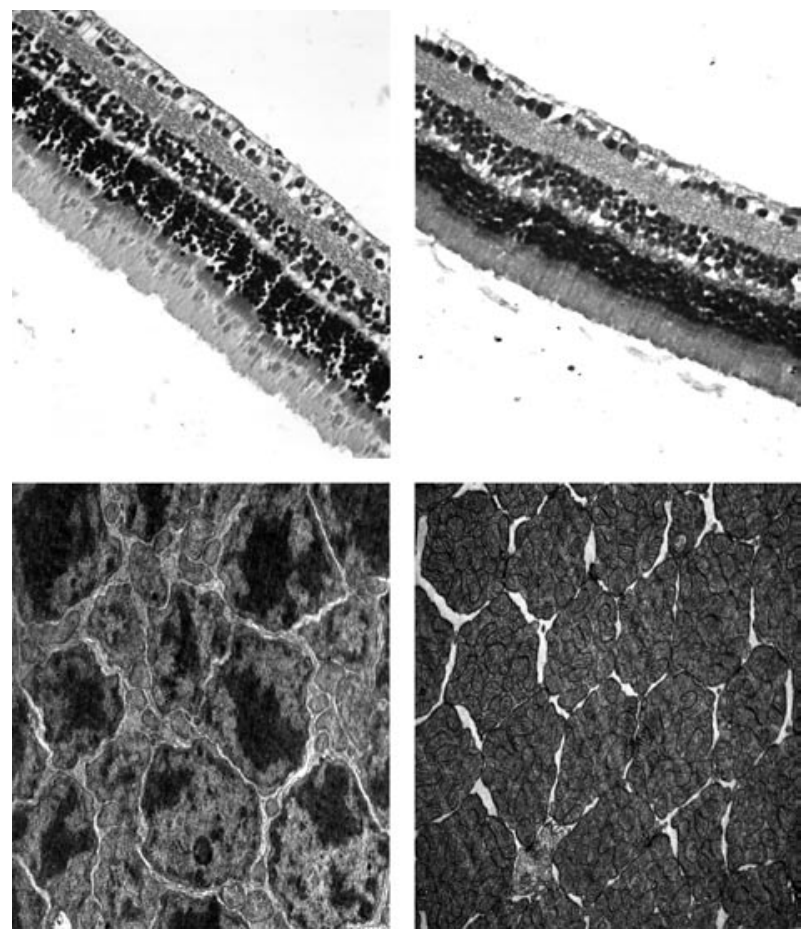

Fig. 1. [Control retina] Up Left; Normal histological appearance in retina (HE; $\times 40)$, Up Right; no TUNEL-positive cell were found (TUNEL; $\times 40$ ), Bottom Left; electron micrograph of INL cells normal ultrastructural appearance $(\times 8,000)$, Bottom Right; normal ultrastructural appearance in PRL cells $(\times 10,000)$.

in GCL than in the other treatment groups (Fig. 4). As shown in Table 2, treatment with PGA yielded statistically significantly lower apoptotic cell counts than the $\mathrm{NaCl}$-treated group in GCL, INL, and $\mathrm{ONL}(P<0.05)$. Also, there were significantly better results in the travoprost treatment group compared to the other prostaglandin analogues, particularly in INL and ONL. 

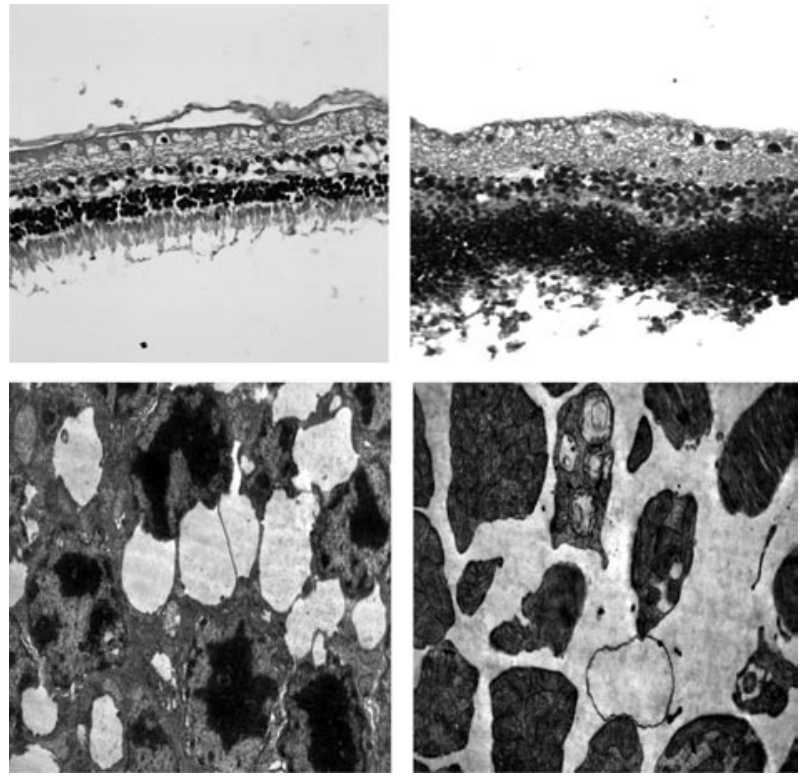

Fig. 2. $[0.9 \% \mathrm{NaCl}$ treated group] Up Left; degeneration in PRL and nuclear condensation in GCL, INL, ONL, and edema in INL (HE; ×40), Up Right; TUNELpositive cells appear dark brown in GCL, INL, and ONL (TUNEL; $\times 40$ ), Bottom Left; highly intercellular space distention and lightly nuclear chromatin condensation in INL $(\times 6,656)$, Bottom Right; extracellular edema and mitochondrial degeneration in PRL $(\times 10,000)$.

\section{Transmission electron microscopy}

In the control group, electron microscopic features of all cells from all layers of the retina were normal in appearence (Fig. 1). In the NaCl-treated group, in INL, nuclear condensation, and dilatation of intercellular spaces were obvious (Fig. 2). In PRL, there was extracellular edema and mitochondrial degeneration (Fig. 2). In all of the treatment groups, in INL there was nuclear condensation and intercellular space distention, but these alterations were mild compared to the $\mathrm{NaCl}$-treated ischemia group (Figs. 3, 4, and 5). In PRL, the ultrastructure of cells were normal in all prostaglandin analoguetreated groups as shown in Figs. 3, 4, and 5.

\section{Vitreous XO measurements}

The activity of $\mathrm{XO}$ was significantly different among the study groups $(P<0.05)$. Dual comparisons between groups show that there was a statistically significant difference between the $\mathrm{NaCl}$-treated group and the others $(P<0.05)$ (Fig. 6). On the other hand, the measured XO
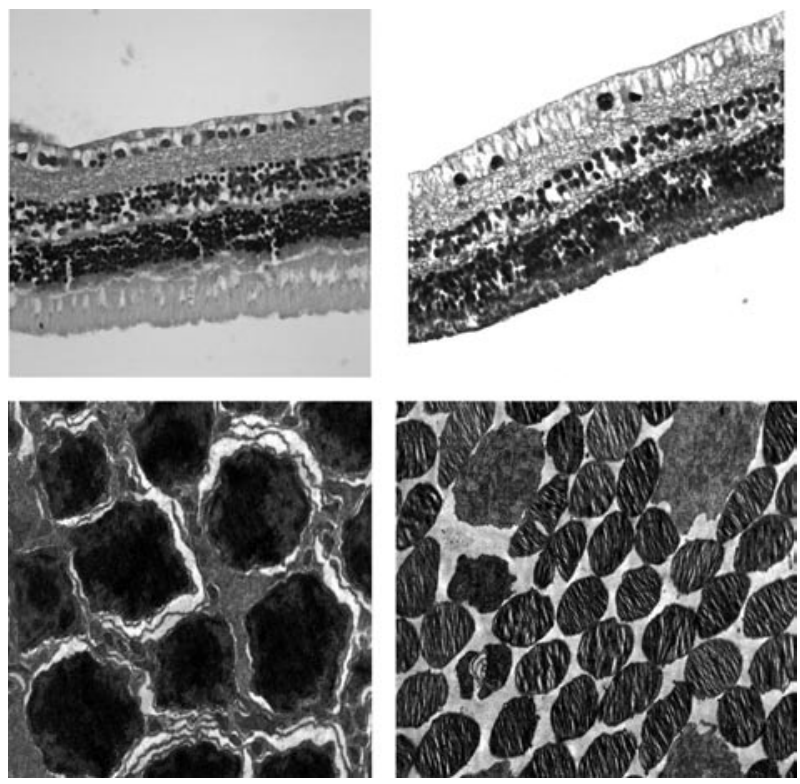

Fig. 3. [Bimatoprost treated group] Up Left; edematous transparant areas in PRL (HE; ×40),Up Right; a few TUNELpositive cells in GCL, INL, and ONL (TUNEL; $\times 40$ ), Bottom Left; Bimatoprost; mild intercellular space distention and lightly nuclear chromatin condensation in INL $(\times 8,000)$, Bottom Right; normal ultrastructural appearance in PRL cells $(\times 6,300)$.

activity in the prostaglandin-treated groups was higher than the control group, but the difference was not statistically significant $(P>0.05)$. Similarly, we did not detect any statisitically significant differences among groups treated with prostaglandin analogues $(P>0.05)$.

\section{Discussion}

As in most tissues, there are highly complex mechanisms for the regulation of retinal circulation. The regulation system is under the control of many different local and systemic factors. Since the retinal tissue lacks vascular innervation, retinal arterial tone is largely regulated by local factors [17]. Previous studies have shown that ROS produced during ischemia activate cyclo-oxygenase and released prostaglandins mediate the vasodilator action of free radicals in the eye [17].

Interruption of blood supply results in ischemic injury which rapidly damages metabolically active tissues. Paradoxically, restoration of blood flow to the ischemic tissue initiates a cascade of events that may lead to ad- 

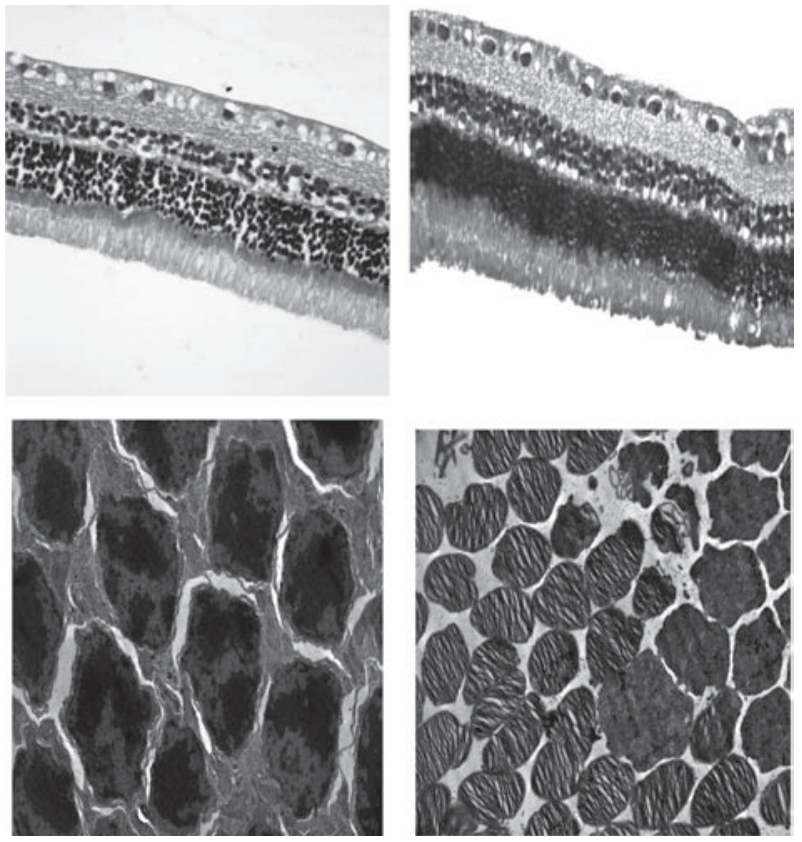

Fig. 4. [Latanoprost treated group] Up Left; Normal histological appearance in retina (HE; $\times 40)$, Up Right; TUNEL-positive cells at INL, ONL, and more prominent in GCL (TUNEL; $\times 40$ ), Bottom Left; mild intercellular space distention and lightly nuclear chromatin condensation in INL $(\times 6,300)$, Bottom Right; normal ultrastructural appearance cells and few degenerative cells in PRL $(\times 6,300)$.
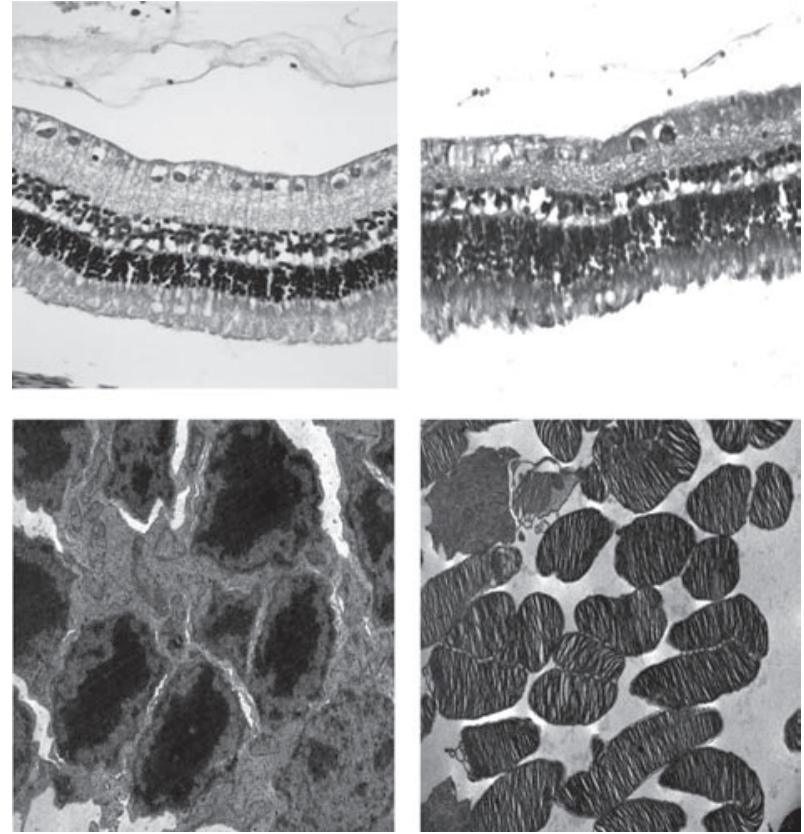

Fig. 5. [Travoprost treated group] Up Left; minimal edema in ONL and mild edematous transparent areas in PRL (HE; $\times 40$ ), Up Right; TUNEL-positive cells were rarely noticed in INL and ONL (TUNEL; ×40), Bottom Left; lightly intercellular space distention and nuclear condensation in INL cells $(\times 8,000)$, Bottom Right; normal ultrastructural appearance cell segments in PRL $(\times 6,300)$.

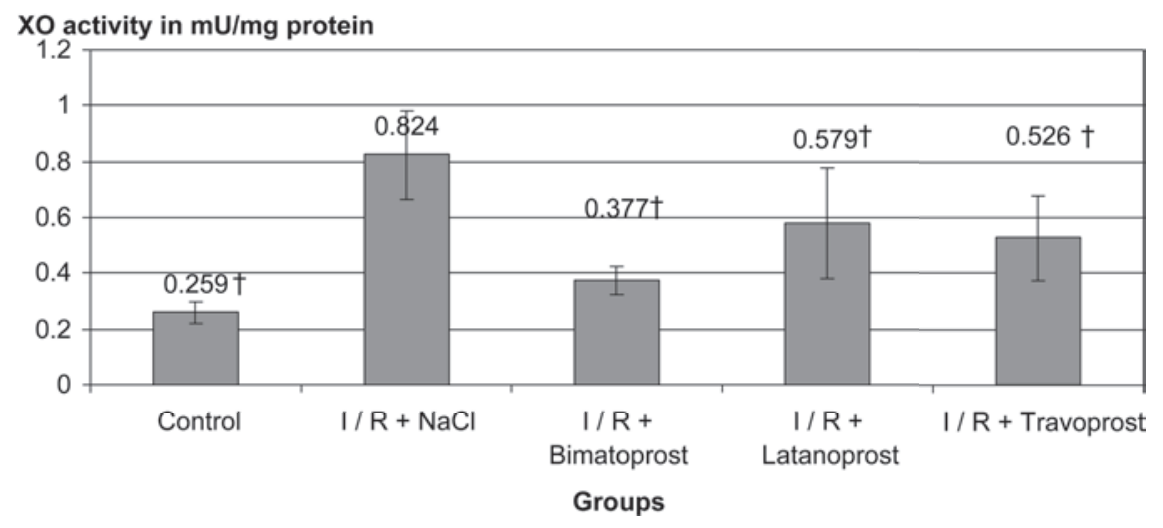

Fig. 6. Vitreous xanthine oxidase activity assay among groups. I/R: Ischemia and reperfusion, $\dagger$ : statistically significant compared to $\mathrm{I} / \mathrm{R}+\mathrm{NaCl}$ group $(P<0.05)$.

ditional cell injury which is known as reperfusion injury [22]. A growing body of evidence indicates that the tissue injury observed after reperfusion is due to the reintroduction of oxygen rather than a delayed manifestation of injury caused by ischemia [31, 35].

Up to now, various experimental designs have been described for the induction of ischemia-reperfusion damage in the retina, as vessel occlusion by clamping $[1,8$, $9,13,24,28,30,32,33]$. In the present study, we used the method of raising intraocular pressure above the arterial opening pressure. This method enables easy reversible occlusion with visually controlled blood flow. 
Table 2. Mean \pm SEM of apoptotic cell counts in different layers of retina among groups

\begin{tabular}{llcc}
\hline Group & GCL & INL & ONL \\
\hline Control & $0.0 \pm 0$ & $0.0 \pm 0$ & $0.0 \pm 0$ \\
Ischemia + NaCl & $4.5 \pm 0.6^{\mathrm{a})}$ & $44.8 \pm 4.6^{\mathrm{a})}$ & $194.57 \pm 18.4^{\mathrm{a})}$ \\
Ischemia + Bimatoprost & $1.4 \pm 0.4^{\mathrm{a}, \mathrm{b})}$ & $27.9 \pm 2.4^{\mathrm{a}, \mathrm{b}, \mathrm{c})}$ & $33.42 \pm 3.5^{\mathrm{a}, \mathrm{b}, \mathrm{c}, \mathrm{d})}$ \\
Ischemia + Latanoprost & $1.8 \pm 0.3^{\mathrm{a}, \mathrm{b})}$ & $24.4 \pm 2.6^{\mathrm{a}, \mathrm{b}, \mathrm{c})}$ & $25.19 \pm 2.2^{\mathrm{a}, \mathrm{b}, \mathrm{c})}$ \\
Ischemia + Travoprost & $1.2 \pm 0.4^{\mathrm{a}, \mathrm{b})}$ & $15.9 \pm 1.5^{\mathrm{a}, \mathrm{b})}$ & $13.69 \pm 2.3^{\mathrm{a}, \mathrm{b})}$ \\
\hline
\end{tabular}

GCL: Ganglion cell layer, INL: Inner nuclear layer, ONL: Outer nuclear layer. ${ }^{a)}$ : Statistically significant compared to control group $P<0.05{ }^{~ b)}$ : Statistically significant compared to $\mathrm{I} / \mathrm{R}$ and $\mathrm{NaCl}$ treatment group $P<0.05$. ${ }^{\mathrm{c})}$ : Statsitically significant compared to $\mathrm{I} / \mathrm{R}$ and travoprost treatment group $P<0.05$. d): Statistically significant compared to I/R and latanoprost treatment group $P<0.05$.

Also elucidation of surgical operation is another advantage of this method. We applied $60 \mathrm{~min}$ of ischemia, which should have been sufficient to have induced substantial ischemic damage.

It has been suggested that both apoptosis and necrosis are involved in I/R-induced neuronal damage [9]. During I/R, apoptosis plays a major role because oxygenderived reactive species (ROS) are known to trigger apoptosis $[37,38]$. Several studies have shown that application of exogenous free radical scavengers [3,9] and topically applied medications including PGA may reduce $\mathrm{I} / \mathrm{R}$-induced damage to the retina [2, 20, 26, 29].

Nakanishi et al. showed that latanoprost rescued cells from apoptosis, secondary to serum deprivation, by inhibiting caspase-3, probably mediated by the mitogenactivated protein kinase pathway coupled to FP receptors in a dose-dependent manner [26]. In our study, we detected a significant alteration in the $\mathrm{NaCl}$ treated group compared to the control group. These alterations were decrements in thickness of all layers except the INL layer, and the total retinal thickness was significantly thinner in the $\mathrm{NaCl}$-treated group than in the control group. Meanwhile, treatment with PGA provided a defence mechanism which was statistically significant in ONL and PRL, as shown in Table 1. On the other hand, unoprostone isopropyl, is also a PGF2 $\alpha$-related ocular hypotensive, and Mukuno et al. showed it has an antiapoptotic effect which works through the Akt or/and protein kinase $\mathrm{G}$ pathway, unlike latanoprost [25]. Probably, PGF2 $\alpha$-related compounds have diverse intracellular signaling pathways specific for each derivative.

Guenoun et al. compared PGA, in vitro, with regard to their protective effects against benzalkonium chloride (BAC) toxicity on conjunctiva-derived epithelial cells [14]. They found that latanoprost and travoprost have the potential to protect on human conjunctiva-derived epithelial cells from BAC toxicity. This property could not be documented for bimatoprost because of its low toxicity, making a protective effect impossible to reveal. The protective effect of PGA has been explained as inhibition of the proapoptotic effects of BAC through the oxidative stress pathways. In our study, in the investigated sections, we also counted the apoptotic cell counts in GCL, INL, and ONL, and we detected statistically significant differences among and between the groups as shown in Table $2(P<0.05)$. We also noticed that in the travoprost treatment group the apoptotic cell count was significanly lower than in the other analogue treatment groups $(P<0.05)$. Generally, the order of groups from minimum to maximum apoptotic cell counts was: travoprost $<$ latanoprost $<$ bimatoprost $<\mathrm{NaCl}$.

Glutamate has neurotoxic potential and it appears to be related to excessive calcium influx through ionotropic receptor stimulation and the subsequent activation of enzymes such as XO, nitric oxide (NO) synthase and phospholipase A2. These different enzymes, respectively, produce superoxide anions, NO and arachidonic acid (AA) that are neurotoxic in various experimental models [7, 23, 42]. However, Drago et al. clearly documented that latanoprost may protect retinal cells agains glutamate toxicity at particular concentrations, probably through the blockade of glutamate receptors. They speculated that the in vivo neuroprotective activity of PGA may be the result of multiple actions on different 
biological targets [10]. In our study, probably inhibition of these pathways with PGA yielded significantly lower levels of $\mathrm{XO}$ in the vitreous. As a result of this reduction, the retinas of the animals were exposed to relatively low levels of ROS, and we observed a relatively low number of apoptotic cells in the retinal layers. However, we also noticed that some of the medications we used were more effective on some retinal layers, as shown in Tables 1 and 2. Even though this can be accepted as a coincidence, a relatively high affinity of a particular PGA to certain retinal cells and layers is another possibility. Moreover, as mentioned by Drago et al., the in vivo neuroprotective potential of these agents could be the result of multiple actions on different biological targets and their variable potency on different targets could be related to their chemical compositions [10].

The presence of $\mathrm{XO}$ in the endothelium of retinal vessels and in the photoreceptor layers of human and bovine retina has recently been documented [12]. Inhibitors of XO have been successfully used to reduce ischemiainduced changes in model systems [32]. In our study, we detected significantly lower levels of XO activity in the PGA treatment groups. Although, we looked for differences between treatment groups, we could not find any statistically significant differences $(P>0.05)$ (Fig. 6). However, the effect of the three PGAs on vitreal and retinal anti-oxidant enzymes could be the subject of another experimental study.

Although there is substantial evidence that many oxidative pathways contribute to damage resulting from $I / R$, it seems unlikely that any one pathway is sufficiently critical to define the outcome. The present results confirm that topically applied PGA acts as a neuroprotective agent against retinal $\mathrm{I} / \mathrm{R}$. This conclusion is based on the finding that the treatment of animals for one week with PGA reduced the histological alterations which occur after ischemia. Moreover, the rationale for the protection achieved by topical PGA is supported by the observation that $\mathrm{I} / \mathrm{R}$ induced increase of vitreal $\mathrm{XO}$ activity was counteracted by these medications.

\section{Acknowledgment(s)}

Authors have no financial or proprietary interest in any instrument or products used in this study. This study is supported by Inonu University Scientific Research Fund (2007-12).

\section{References}

1. Agardh, C.D., Gustavsson, C., Hagert, P., Nilsson, M., and Agardh, E. 2006. Expression of antioxidant enzymes in rat retinal ischemia followed by reperfusion. Metabolism 55: 892-898.

2. Aktaş, Z., Gürelik, G., Akyürek, N., Onol, M., and Hasanreisoğlu, B. 2007. Neuroprotective effect of topically applied brimonidine tartrate $0.2 \%$ in endothelin-1-induced optic nerve ischaemia model. Clin. Experiment. Ophthalmol. 35: 527-534.

3. Baudouin, C., Pisella, P.J., Ettaiche, M., Goldschild, M., Becquet, F., Gastaud, P., and Droy-Lefaix, M.T. 1999. Effects of EGb761 and superoxide dismutase in an experimental model of retinopathy generated by intravitreal production of superoxide anion radical. Graefes Arch.Clin. Exp. Ophthalmol. 237: 58-66.

4. Bergmeyer, H.U., Gawehen, K., and Grassl, M. 1974. Enzymatic assay of xanthine oxidase. pp. 521-522. In: Methods of Enzymatic Analysis, 2nd edition, Vol. I (Bergmeyer, H.U. ed.), Academic Press, New York.

5. Bonne, C., Muller, A., and Villain, M. 1998. Free radicals in retinal ischemia. Gen. Pharmacol. 30: 275-280.

6. Bresnick, G.H., Engerman, R., Davis, M.D., de Venecia, G., and Myers, F.L. 1976. Patterns of ischemia in diabetic retinopathy. Trans. Sect. Ophthalmol.Am. Acad.Ophthalmol. Otolaryngol. 81: 694-709.

7. Chi, D.W. 1988. Calcium-mediated neurotoxicity: relationship to specific channel types and role in ischemic damage. Trends Neurosci. 11: 465-467.

8. Daugeliene, L., Niwa, M., Hara,A., Matsuno, H., Yamamoto, T., Kitazawa, Y., and Uematsu, T. 2000. Transient ischemic injury in the rat retina caused by thrombotic occlusionthrombolytic reperfusion. Invest. Ophthalmol. Vis. Sci. 41: 2743-2747.

9. Dilsiz, N., Sahaboglu, A., Yildiz, M.Z., and Reichenbach, A. 2006. Protective effects of various antioxidants during ischemia-reperfusion in the rat retina. Graefes Arch. Clin. Exp. Ophthalmol. 244: 627-633.

10. Drago, F., Valzelli, S., Emmi, I., Marino, A., Scalia, C.C., and Marino, V. 2001. Latanoprost exerts neuroprotective activity in vitro and in vivo. Exp. Eye Res. 72: 479-486.

11. Flammer, J. and Orgül, S. 1998. Optic nerve blood-flow abnormalities in glaucoma. Prog. Retin. Eye Res. 17: 267-289.

12. Fox, N.E. and van Kuijk, F.J. 1998. Immunohistochemical localization of xanthine oxidase in human retina. Free Radic. Biol. Med. 24: 900-905.

13. Gelbach, P.L. and Purple, R.L. 1994. A paired comparison of two models of experimental retinal ischemia. Curr. Eye Res. 13: 597-602.

14. Guenoun, J.M., Baudouin, C., Rat, P., Pauly, A., Warnet, J.M., and Brignole-Baudouin, F. 2005. In vitro comparison of cytoprotective and antioxidative effects of latanoprost, 
travoprost, and bimatoprost on conjunctiva-derived epithelial cells. Invest. Ophthalmol. Vis. Sci. 46: 4594-4599.

15. Guo, L., Moss, S.E., Alexander, R.A., Ali, R.R., Fitzke, F.W., and Cordeiro, M.F. 2005. Retinal ganglion cell apoptosis in glaucoma is related to intraocular pressure and IOP induced effects on extracellular matrix. Invest. Ophthalmol. Vis. Sci. 46: 175-182.

16. Hangai, M., Yoshimura, N., and Honda, Y. 1996. Increased cytokine gene expression in rat retina following transient ischemia. Ophthalmic Res. 28: 248-254.

17. Hardy, P., Beauchamp, M., Sennlaub, F., Gobeil, F. Jr., Tremblay, L., Mwaikambo, B., Lachapelle, P., and Chemtob, S. 2005. New insights into the retinal circulation: inflammatory lipid mediators in ischemic retinopathy. Prostaglandins Leukot. Essent. Fatty Acids 72: 301-325.

18. Jo, N., Wu, G.S., and Rao, N.A. 2003. Upregulation of chemokine expression in the retinal vasculature in ischemiareperfusion injury. Invest. Ophthalmol. Vis. Sci. 44: 40544060 .

19. Kuriyama, H., Waki, M., Nakagawa, M., and Tsuda, M. 2001. Involvement of oxygen free radicals in experimental retinal ischemia and the selective vulnerability of retinal damage. Ophthalmic Res. 33: 196-202.

20. Lafuente, M.P., Villegas-Pérez, M.P., Mayor, S., Aguilera, M.E., Miralles de Imperial, J., and Vidal-Sanz, M. 2002. Neuroprotective effects of brimonidine against transient ischemia-induced retinal ganglion cell death: a dose response in vivo study. Exp. Eye Res. 74: 181-189.

21. Lowry, O.H., Rosebrough, N.J., Farr, A.L., and Randall, R.J. 1951. Protein measurement with the folin phenol reagent. J. Biol. Chem. 193: 265-275.

22. Mallick, I.H., Yang, W., Winslet, M.C., and Seifalian, A.M. 2004. Ischemia-reperfusion injury of the intestine and protective strategies against injury. Dig. Dis. Sci. 49: 1359-1377.

23. Meldrum, B. and Garthwaite, J. 1990. Excitatory aminoacid neurotoxicity and neurodegenerative disease. Trends Pharmacol. Sci. 11: 379-383.

24. Mosinger, J.L. and Olney, J.W. 1989. Photothrombosisinduced ischemic neuronal degeneration in rat retina. Exp. Neurol. 105: 110-113.

25. Mukuno, H., Nakamura, M., Kanamori, A., Nagai, A., Negi, A., and Seigel, G. 2004. Unoprostone isopropyl rescues retinal progenitor cells from apoptosis in vitro. Curr. Eye Res. 29: 457-464.

26. Nakanishi, Y., Nakamura, M., Mukuno, H., Kanamori, A., Seigel, G.M., and Negi, A. 2006. Latanoprost rescues retinal neuro-glial cells from apoptosis by inhibiting caspase-3, which is mediated by $\mathrm{p} 44 / \mathrm{p} 42$ mitogen-activated protein kinase. Exp. Eye Res. 83: 1108-1117.

27. Okisaka, S., Murakami, A., Mizukawa, A., and Ito, J. 1997. Apoptosis in retinal ganglion cell decrease in human glaucomatous eyes. Jpn. J. Ophthalmol. 41: 84-88.

28. Osborne, N.N., Casson, R.J., Wood, J.P., Chidlow, G., Graham, M., and Melena, J. 2004. Retinal ischemia: mechanisms of damage and potential therapeutic strategies. Prog. Retin. Eye Res. 23: 91-147.

29. Osborne, N.N., DeSantis, L., Bae, J.H., Ugarte, M., Wood,
J.P., Nash, M.S., and Chidlow, G. 1999. Topically applied betaxolol attenuates NMDA-induced toxicity to ganglion cells and the effects of ischemia to the retina. Exp. Eye Res. 69: 331-342.

30. Oz, O., Gürelik, G., Akyürek, N., Cinel, L., and Hondur, A. 2005. A short duration transient ischemia induces apoptosis in retinal layers: an experimental study in rabbits. Eur. $J$. Ophthalmol. 15: 233-238.

31. Parks, D.A. and Granger, D.N.1986. Contributions of ischemia and reperfusion to mucosal lesion formation. Am. J. Physiol. 250: 749-753.

32. Rosenbaum, D.M., Rosenbaum, P.S., Singh, M., Gupta, G., Gupta, H., Li, B., and Roth, S. 2001. Functional and morphologic comparison of two methods to produce transient retinal ischemia in the rat. J. Neuroophthalmol. 21: 62-68.

33. Sakamoto, K., Yonoki, Y., Kuwagata, M., Saito, M., Nakahara, T., and Ishii, K. 2004. Histological protection against ischemia-reperfusion injury by early ischemic preconditioning in rat retina. Brain Res. 1015: 154-160.

34. Sanchez, R.N., Chan, C.K., Garg, S., Kwong, J.M., Wong, M.J., Sadun, A.A., and Lam, T.T. 2003. Interleukin-6 in retinal ischemia reperfusion injury in rats. Invest. Ophthalmol. Vis. Sci. 44: 4006-4011.

35. Sasaki, M. and Joh, T. 2007. Oxidative stress and ischemiareperfusion injury in gastrointestinal tract and antioxidant, protective agents. J. Clin. Biochem. Nutr. 40: 1-12.

36. Schwartz, B., Takamoto, T., and Nagin, P. 1991. Photogrammetry and Image Analysis of Optic Disc, Retinal Nerve Fiber Layer and Retinal Circulation in Glaucoma, Saunders, Philadelphia.

37. Sugawara, T. and Chan, P.H. 2003. Reactive oxygen radicals and pathogenesis of neuronal death after cerebral ischemia. Antioxid. Redox Signal. 5: 597-607.

38. Szabo, M.E., Droy-Lefaix, M.T., Doly, M., Carré, C., and Braquet, P. 1991. Ischemia and reperfusion induced histologic changes in the rat retina. Demonstration of a free radical-mediated mechanism. Invest. Ophthalmol. Vis. Sci. 32: 1471-1478.

39. Warner, D., Sheng, H., and Batinic-Haberle, I. 2004. Oxidants, antioxidants and the ischemic brain. J. Exp. Biol. 207: 3221-3231.

40. Vorwerk, C.K., Lipton, S.A., Zurakowski, D., Hyman, B.T., Sabel, B.A., and Dreyer, E.B.1996. Chronic low-dose glutamate is toxic to retinal ganglion cells. Toxicity blocked by memantine. Invest. Ophthalmol. Vis. Sci. 37: 16181624.

41. Yoneda, S., Tanihara, H., Kido, N., Honda, Y., Goto, W., Hara, H., and Miyawaki, N. 2001. Interleukin-1beta mediates ischemic injury in the rat retina. Exp. Eye Res. 73: 661667.

42. Zeevalk, G.D. and Nicklas, W.J. 1990. Chemically induced hypoglycemia and anoxia: relationship to glutamate receptor mediated toxicity in retina. Pharmacol. Exp. Therapeut. 1253: 1285-1292.

43. Zheng, L., Gong, B., Hatala, D.A., and Kern, T.S. 2007. Retinal ischemia and reperfusion causes capillary degeneration: similarities to diabetes. Invest. Ophthalmol. Vis. Sci. 48: 361-367. 